valuable for burns surgery; as well as preventing hypotension, it may make a difficult endotracheal intubation unnecessary. ${ }^{12}$ It is also a good choice for many minor paediatric operations and procedures, such as intravenous cannulation on an uncooperative child, and for certain radiological investigations. Finally, it may be especially useful in ill patients for the induction of anaesthesia or for short operations on the body surface.

Ketamine is easy to administer. In countries in which there are few skilled anaesthetists there will be a temptation to use ketamine widely without an anaesthetist. ${ }^{13}$ Though ketamine has a considerable margin of safety, occasionally the airway becomes obstructed. There can be respiratory depression. A letter in this issue (p. 709) reports that, as with any other anaesthetic, the untoward can occur with little or no warning. Thus the use of ketamine does not, in any respect, reduce the need for continuous vigilance and skilled care. 1 Corssen, G., Miyasaka, M., and Domino, E. F., Anesthesia and Analgesia.
Current Researches, 1968, 47, 746.

2 Langrehr, D., Alai, P., Andjelkovie, J., and Kluge, I., Der Anaesthesist, 1967, 16, 308.

${ }^{3}$ Dundee, J. W., et al., Lancet, 1970, 1, 1370.

4 Morgan, M., Loh, L., Singer, L., and Moore, P. H., Anaesthesia, 1971, 26, 158 .

${ }^{5}$ Brice, D. D., Hetherington, R. R., and Utting, J. E., British fournal of Anaesthesia, 1970, 42,535.

- Wilson, R. D., Traber, D. L., and Evans, B. L., Anesthesia and Analgesia, Current Researches, 1969, 48, 995.

7 Evans, J., Rosen, M., Weeks, R. D., and Wise, C., Lancet, 1971, 1, 40.

8 Rapkin, R. H., Lancet, 1971, 1, 594.

Wilson, G. H., Fotias, N. A., and Dillon, J. B., American fournal of Roentgenology, Radium Therapy and Nuclear Medicine, 1969, 106, 434.

10 Wilson, G. H., Lancet, 1971, 1, 243.

${ }^{11}$ Pontopiddan, H., and Beecher, H. K., Fournal of American Medical Association, 1960, 174, 2209.

12 Corssen, G., and Oget, S., Anesthesia and Analgesia, Current Researches,

1971, 50, 95.
13 Phillips, I. A., Seruvatu, S. G., Rika, P. N., and Tirikula, U., Anaesthesia, $1970,25,36$.

\section{Penicillin-resistant Pneumococci}

It has always been an article of faith in the field of chemotherapy that neither group A haemolytic streptococci nor pneumococci are capable of becoming resistant to penicillin. Indeed it is one of the great virtues of penicillin that in general bacteria do not develop resistance to it, as to so many other antibiotics. The only serious exception is the gonococcus. Resistance in staphylococci is not acquired, but the result of selection. Other important species are just as sensitive as they were in the old days: pneumococci were found by $M$. Finland and his colleagues in studies of recently isolated strains to possess the same degree of sensitivity in $1957^{1}$ and again in $1965^{2}$ as they had before 1949. Any threat to the continuance of this happy position would prejudice the treatment not only of pneumonia but of various other infections in which pneumococci are involved.

A faint but unmistakable warning that this position may change comes in a recent report by D. Hansman and his colleagues from Australia. ${ }^{3}$ There have been two single isolations of resistant strains in Australia itself, but this report concerns the prevalence of a resistant type in two villages in New Guinea. In this area pneumococcal pneumonia is common, and, because the inhabitants living in isolated areas may die of it before obtaining medical attention, penicillin prophylaxis has been attempted. It is mentioned that in the two villages studied 507 people had re- ceived 1,357 courses of procaine penicillin in the past ten years. In the trial described in the present report $1,200,000$ units of procaine penicillin were given to adults and 600,000 units to children once a month. It may be questioned in passing whether this regimen is calculated to have the effect desired. A single dose cannot be expected to eliminate the organism from the air passages, and, since its effect would last for two days at most, it would leave the patient unprotected until the next was due. Benzathine penicillin, the effect of which is much more prolonged, might have been a better choice for this kind of use. However, this treatment was given in one of two neighbouring villages, and throat swabs were taken monthly from both.

During the next $3 \frac{1}{2}$ months 15 resistant strains were isolated, 11 from the treated village and 4 from the untreated, 2 of which were from actual infections. All were of type 4, and were inhibited only by $0.5 \mu \mathrm{g} / \mathrm{ml}$ of penicillin, a degree of resistance exceeding the normal by a factor of 25 . Their sensitivity to ampicillin and to cephaloridine was also reduced by factors of $2-4$ and 10 respectively. Resistance was stable, persisting after repeated cultural transfer. No information is given about the efficacy of penicillin prophylaxis or of treatment of those patients infected by resistant strains.

The importance of this observation lies in showing that either more resistant strains exist or that mutation to resistance is possible in this species in the rather unusual conditions existing in New Guinea. Abnormal resistance has occasionally been detected only after many years of use of an antibacterial drug: the present resistance of meningococci to sulphonamides and of gonococci to penicillin are examples. Now it seems advisable that recent isolates of pneumococci in other parts of the world should be accurately examined for any tendency to this change.

\footnotetext{
1 Jones, W. F., and Finland, M., American fournal of Medical Sciences, 1957, 233, 312.

Kislak, J. W., Razavi, L. M. B., Daly, A. K., and Finland, M., American Fournal of Medical Sciences, 1965, 250, 261.

3 Hansman, D., Glasgow, H., Sturt, J., Devitt, L., and Douglas, R., New England fournal of Medicine, 1971, 284, 175.
}

\section{Bed Rest in Rheumatoid Arthritis}

Rheumatoid arthritis is an inflammatory disease which affects the general health, often causing anaemia, loss of weight, poor appetite, and disturbance of the sense of wellbeing. It also causes inflammation in from one to some 70 joints of the body. These changes may remit in days, weeks, or months, or continue relentlessly to the patient's death, or remit and relapse from time to time.

In such a variable and unpredictable disease, for which there is no certain cure, accurate prognosis is rarely possible and treatment must be largely empirical. For these reasons the assessment of different forms of therapy is notoriously difficult, for spontaneous relapse or remission is a part of the natural history of the disease, and the anxiety and depression from which patients are apt to suffer may affect therapeutic results. Nevertheless, a candidate asked in the final examination to discuss the treatment of active rhelimato: $d$ arthritis who did not mention rest in general and bed rest in particular would probably have failed. What is the basis for this commonly accepted belief? Is it faith or fact? 
Rheumatologists see many patients who have made their condition worse by overuse of the joints and who, in an attempt to work and walk off the early symptoms of their disease, have instead worked and walked them on. In an attempt to keep going at all costs they have aggravated the disease and sometimes precipitated their admission to hospital. It has been observed ${ }^{1}$ that patients with acute rheumatoid arthritis in sufficiently active form to warrant their early admission to hospital, and who have therefore. been diagnosed and treated relatively early in the course of their disease, have done better than those with less acute disease who struggled on for months and years, undiagnosed and untreated. In contrast, patients who have early given up the struggle and returned to bed and chair have done equally badly or even worse, developing contractures and pressure sores. Every patient with this disease is an individual problem, and rigid rules can seldom be applied. Even if they are the patient usually breaks them.

Famous authorities of their day such as John Hunter, ${ }^{2}$ Hugh Thomas, ${ }^{3}$ and Sir Robert Jones, ${ }^{4}$ warned against the dangers of excessive use of inflamed joints. Many subsequent workers $^{5-10}$ have advocated temporary immobilization of the acutely affected joints in light plaster casts. In an attempt to assess the value of such treatment, $R$. E. H. Partridge and J. R. Duthie ${ }^{11}$ in 1963 compared 34 patients with active rheumatoid arthritis treated in bed for four weeks by immobilization in unpadded plaster casts fixed in position by circular cuffs, no physiotherapy being given over this period, with 34 similar patients also confined to bed for four weeks but who performed daily active exercises. The range of movement and functional capacity improved in both groups, but disease activity diminished more in the first group, particularly in those patients with much inflammation. No joint ankylosis was seen in either group.

It must be emphasized that in such a variable disease as rheumatoid arthritis it is hard to assemble two truly comparable groups of patients, and it is not uncommon to see one patient doing badly on a regimen which suits another admirably. When in doubt, physicians have in the past turned to that classic text on the subject, Rheumatoid Arthritis, by C. L. Short, W. Bauer, and W. E. Reynolds, ${ }^{12}$ of Boston, Mass. Now the Massachusetts Group have once again come to our rescue. Pointing out that there are no published reports on the effect of bed rest as such in rheumatoid arthritis and that bed rest has never been studied as an isolated variable in management, J. A. Mills and colleagues ${ }^{13}$ report a study of 42 rheumatoid patients. Twenty-two were randomly selected to be treated in hospital for a period of 10 weeks without restriction of physical activity. The other 20 were confined to bed in hospital for at least 22 hours a day for the first four weeks of the study and at least 18 hours a day for the remaining six weeks. Ambulation in the latter group was limited to use of bathroom within 20 yards $(18 \mathrm{~m})$ of the bed during the first four weeks and to short walks in the ward thereafter. All received physical treatment and salicylates and only two patients, one in each treatment group, were on prednisone, the dosage of which remained unchanged throughout the study. Every two weeks over the 10-week period a physician unaware of the treatment programme evaluated the results. Joint tenderness, joint swelling, grip strength, walking, stair climbing, and other functional tests were studied and the usual laboratory tests performed. Half or more of the patients improved to some degree, but there was no substantial difference between the two groups, and the degree of improvement was not great in most cases. What improvement there was may have been due to shelter from the worries and disturbances of home life and to regular administration of salicylate rather than to the amount of bed rest in hospital.

This work is a good example of a careful and conscientious study, well performed by a group of workers expert in this field, and it is extraordinary that only now has an attempt been made to measure the effects of that most fundamental form of treatment in rheumatoid arthritis, rest in bed.

1 Duthie, J. J. R., Brown, P. E., Truelove, L. H., Baragar, F. D., and Lawrie, A. J., Annals of the Rheumatic Diseases, 1964, 23, 193. Hunter, J., The Works of fohn Hunter, F.R.S., ed. J. F. Palmer. London, Longman, 1837.

Thomas, H. O. Diseases of the Hip, Knee and Ankle foints, with their Deformities, treated by $a$ New and Efficient Method, 3rd edn. London, Lewis, 1878.

4 Jones, R., British Medical fournal, 1909, 2, 2.

Swaim, L. T., fournal of the American Medical Association, 1934

103, 1589. C. E., Proceedings of the Royal Society of Medicine, 1936, 29, 237.

7 Duthie, J. J. R., Practitioner, 1951, 161, 22.

8 Duthie, J. J. R., Fournal of Bone and Foint Surgery, 1952, 34B, 211. Kelly, M. Medical fournal of Australia, 1953, 2, 95.

Swanson, N., Canadian Medical Association fournal, 1956, 75, 257.

Partridge, R. E. H.. and Duthie, J. J. R., Annals of the Rheumatic Diseases, 1963, 22, 91.

12 Short, C. L., Bauer, W.. and Reynolds, W. E., Rheumatoid Arthritis. Cambridge, Mass., Harvard University Press, 1957.

13 Mills. J. A., Pinals, R. S., Ropes, M. W. Short, C. L. and Sutcliffe, J. New England fournal of Medicine, i971, 284, 453.

\section{Renal Stones in Top People}

In adults nearly all urinary calculi originate in renal papillae, work loose, go down the ureter in a succession of attacks of ureteric colic, and once in the bladder are voided in the urinary stream unless there is obstruction at the bladder neck or prostate. In children, though stones form in the kidney and work down into the bladder in the usual way, they tend to remain there (at least in boys) and grow into bladder stones. In Europe until the turn of the century, as today in some underdeveloped parts of the world, stones were common in children. Cutting for the stone was often necessary in schoolboys, to whom some of the ancient surgeons (including Celsus) restricted their practice. With the end of the nineteenth century childhood bladder stone all but disappeared from Europe, and it is now fast disappearing from less technically advanced parts of the world thanks to improvements in diet. ${ }^{1-3}$

But with the disappearance of childhood bladder stones came a new wave of stones in adults. This was noted all over Europe, and steadily increased, only halting for a few years with each of two world wars. Most of the adults seemed to have but one attack of ureteric colic followed by passage of a stone, and the condition was not regarded too seriously. It was only when detailed follow-up studies were carried out on adults who had passed one stone that it was realized that one stone heralded another. As many as $75 \%$ of patients would get a second stone. Even though there may be nine or ten years between episodes, there is a considerable risk that sooner or later the adult stone-former will need a surgical operation for his stones. ${ }^{-6}$

All adults are not equally at risk. Apart from the special problem of the Bantu races in South Africa, whose freedom from urinary calculus is explicable by their diet, ${ }^{7}$ the incidence of stone in men following different occupations varies greatly. In Czechoslovakia agricultural labourers were found to have fewest stones; sedentary workers, teachers, and health workers three to four times the average in- 